\title{
Capsule endoscopy: New technology that is here to stay
}

\author{
Robert Enns MD FRCPC
}

$\mathrm{C}^{\mathrm{a}}$ apsule endoscopy (CE) has recently been approved as a new technique for the examination of the small intestine. Following approval by the Food and Drug Administration of the United States in August 2001, CE has quickly gained widespread acceptance as the new 'gold standard' for visualization of the small intestine. Food and Drug Administration approval was based on two clinical studies $(1,2)$. The first (1) compared CE with push enteroscopy (PE) (the previous gold standard) in dogs who had nine to 13 beads ( $3 \mathrm{~mm}$ to $6 \mathrm{~mm}$ each) sewn into the small intestine. CE identified more beads (median of six) than PE (median of three), with $64 \%$ sensitivity compared with $37 \%$ sensitivity for PE. The authors concluded that this new method of assessing the small intestine was superior to PE.

The second study (2) evaluated 21 patients (12 women, mean age 61 years) with a history of significant bleeding requiring transfusion (mean transfusion requirements 28 units). The yield of PE was $30 \%$, lower than that of CE (55\%). CE identified all of the lesions defined by PE plus an additional five. All lesions identified by CE were beyond the distal reach of the enteroscope. Patients appeared to prefer CE over PE. All patients had been previously evaluated endoscopically and were considered to be likely to have a small intestinal bleeding site. Although these two studies support CE, there are a variety of concerns to consider. CE was not $100 \%$ sensitive in either study, and small lesions were missed. A second capsule (or alternative studies) should always be considered in the setting of a negative study.

In this issue of the Journal, Tang et al (pages 559-565) from St Michael's Hospital, Toronto, Ontario report their experience of the first 46 capsules performed over a one-year period. Their study is not population-based, because other Toronto institutions were providing a similar service. Concerns about a selection bias are raised because of payment issues.

Their findings demonstrated a yield of $63 \%$ (41\% classified as definite or probable), similar to previous studies with CE (1-5). The variation in yield probably depends on the definition of what constitutes a positive finding. For example, the report by Tang et al defined a 'definite' positive finding as either an ulcer or an active bleeding site. Other studies have included findings such as lymphangiectasia and nonbleeding angioectasia, which may not be the actual bleeding site.

As CE evolves, the definition of positive findings will require a consensus guideline. Until then, discrepancies will be common when one study is compared with another. Moreover, even with strict criteria to define abnormalities, the lack of a placebo or sham procedure in most CE studies results in additional biases. In one of the few studies where a placebo group was used, a 14\% abnormality rate was determined in the placebo group (6).

Tang et al have stressed that a significant number of abnormalities (28\%) found on CE were within reach of a standard endoscopic examination. Our centre noted similar results (7). At first, this is somewhat discouraging and theoretically could raise issues regarding the source of referrals and their endoscopic abilities. Although in some cases this is clearly the issue, in other situations the indications for the procedure and the lesions themselves may necessitate excluding other sources. For instance, Cameron lesions (erosive lesions within a hiatus hernia) rarely bleed significantly but are occasionally the source of obscure bleeding, resulting in anemia. Sometimes, treatment with acid suppression is successful. However, if treatment fails, patients who are being considered for surgery may have a CE before the procedure.

Tang et al have stressed differences between community and university endoscopists by using a definition for community as 'not associated with the university.' Many sites are not officially university-associated; however, they have extremely talented endoscopists and I believe that many of the 'missed' lesions may be secondary to other factors noted above. Whether repeat endoscopic exams should be performed on all patients referred to a 'university centre' for CE is another point of debate. It is true that $28 \%$ of patients had lesions that could have been diagnosed with standard endoscopic examinations; however, does this $28 \%$ justify repeat panendoscopy (PE and colonoscopy) on all patients? Even in these $28 \%$, the capsule examination directed the subsequent endoscopic treatment. Rather than repeating endoscopic studies even a second time, we should consider CE earlier in the algorithm.

A recent comparison (8) of CE and PE reported savings of over 1000 Euro per patient, if the prevalence of disease discovered on CE was $50 \%$, in the setting of obscure bleeding. This strategy was cost-effective in five different countries (United States, France, United Kingdom, Switzerland and Germany) as long as the prevalence of disease on CE was over 30\%.

A recent publication by Pennanzio et al (9) has demonstrated that early CE may have significantly higher yields when performed in the setting of obscure, overt bleeding as opposed 
to waiting and performing the study later. This was not supported by the article by Tang et al in this Journal, because they did not find any differences in yield in overt versus occult bleeding. It would seem logical that capturing the bleeding acutely would likely have higher yields. On the other hand, in the same article by Pennanzio et al, it was demonstrated that most of the patients could be managed medically, supporting the fact that most lesions were due to medically correctable (eg, discontinuation of nonsteroidal anti-inflammatory drugs) issues. These studies have also tried to select patients most likely to benefit from $\mathrm{CE}$ and determine risk stratification. More prospective evaluation of these patients is required to substantiate these results.

\section{REFERENCES}

1. Chong AK, Taylor AC, Miller AM, Desmond PV. Initial experience with capsule endoscopy at a major referral hospital. Med J Aust 2003;178:537-40.

2. Ell C, Remke S, May A, Helou L, Henrich R, Mayer G. The first prospective controlled trial comparing wireless capsule endoscopy with push enteroscopy in chronic gastrointestinal bleeding. Endoscopy 2002;34:685-9.

3. Lewis BS, Swain P. Capsule endoscopy in the evaluation of patients with suspected small intestinal bleeding: Results of a pilot study. Gastrointest Endosc 2002;56:349-53.

4. Scapa E, Jacob H, Lewkowicz S, et al. Initial experience of wirelesscapsule endoscopy for evaluating occult gastrointestinal bleeding and suspected small bowel pathology. Am J Gastroenterol 2002;97:2776-9.

5. Van Gossum A, Hittelet A, Schmit A, Francois E, Deviere J. A prospective comparative study of push and wireless-capsule
Without adequate reimbursement for CE in Canada, this issue will likely take years to resolve. In this time of governmental financial restraint, new medical technology is unlikely to be rapidly embraced by our governing bodies, even if it does demonstrate improved outcomes with decreased resource utilization. When to use CE in the algorithm of obscure gastrointestinal bleeding is a difficult question that requires ongoing study. This study by Tang et al is to be commended in that they have used the new technology, evaluated their results and are trying to determine the best place to use this device. No matter what the conclusion one brings to $\mathrm{CE}$, one thing is clear: this technology is advancing and its applications will likely expand. It is here to stay!

enteroscopy in patients with obscure digestive bleeding. Acta Gastroenterol Belg 2003;66:199-205.

6. Abnormal small bowel findings are common in healthy subjects screened for a multi-center double blind, randomized, placebocontrolled trial using capsule endoscopy. Gastroenterology 2003;14(Suppl 1):A284. (Abst)

7. Go K, Pluta K, Enns R. Impact of capsule endoscopy: How many lesions can be reached with a standard endoscopic exam? Can J Gastroenterol 2004;18(Suppl A):183. (Abst)

8. Mueller E, Schwander B, Bergemann R. Cost effectiveness of capsule endoscopy in diagnosing obscure GI bleeding: An international comparison. Gastrointest Endosc 2004;59:A138 (Abst)

9. Pennazio M, Santucci R, Rondonotti E, et al. Outcome of patients with obscure gastrointestinal bleeding after capsule endoscopy: Report of 100 consecutive cases. Gastroenterology 2004;126:643-53. 


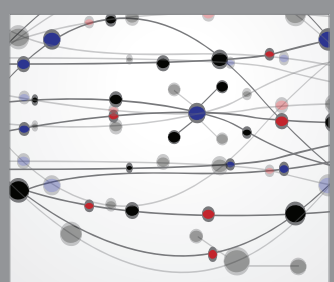

The Scientific World Journal
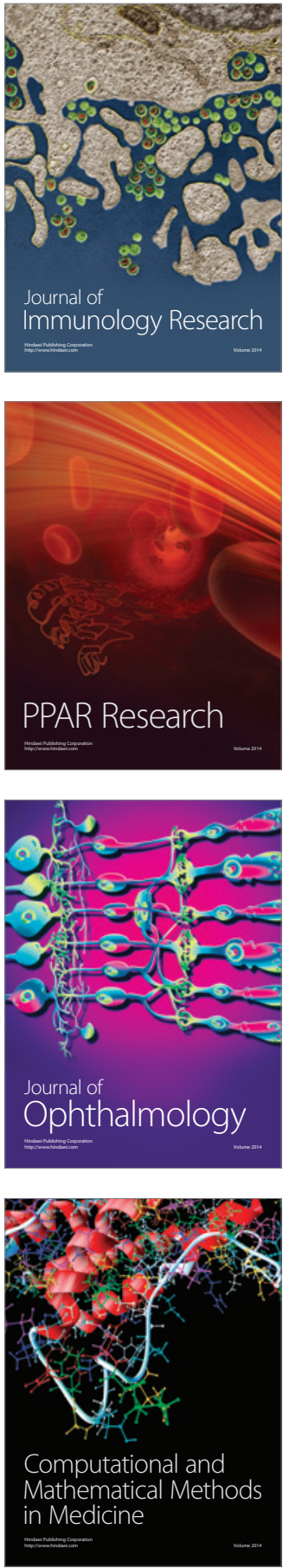

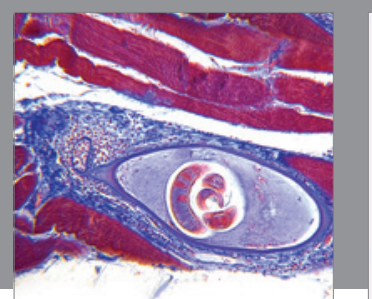

Gastroenterology Research and Practice

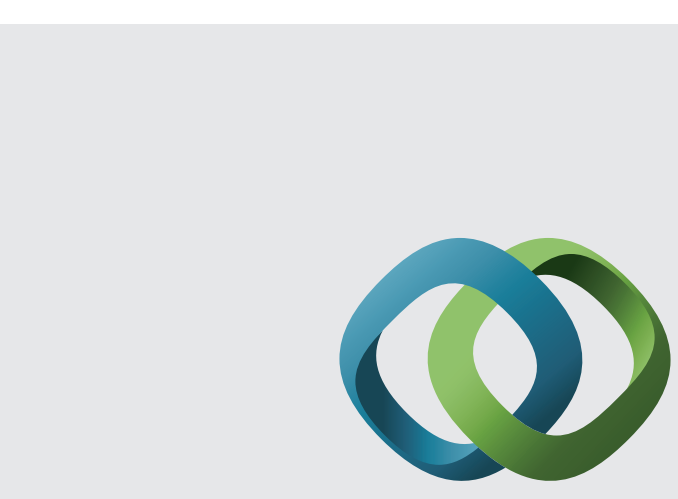

\section{Hindawi}

Submit your manuscripts at

http://www.hindawi.com
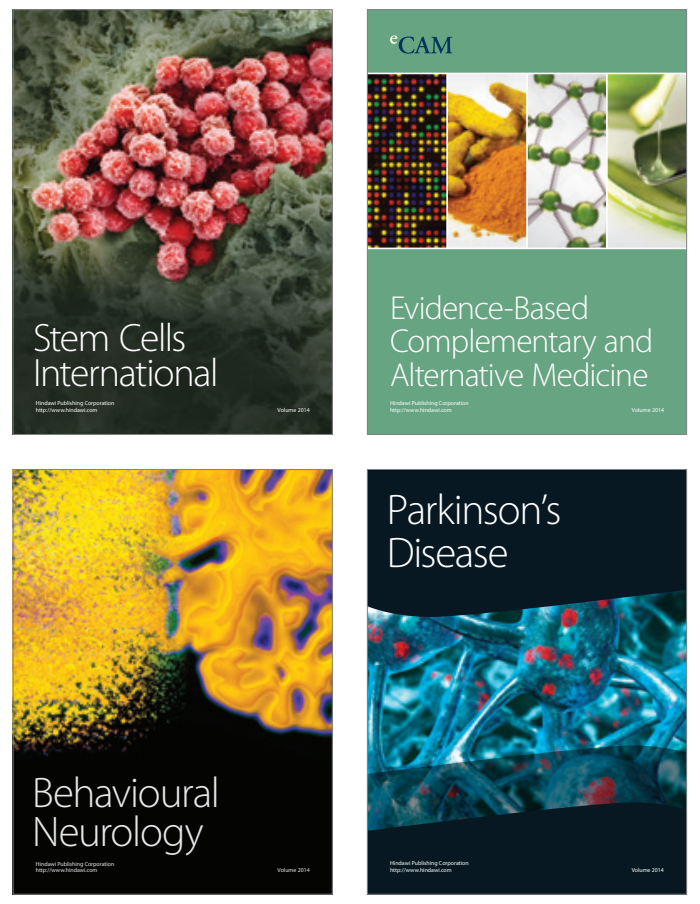
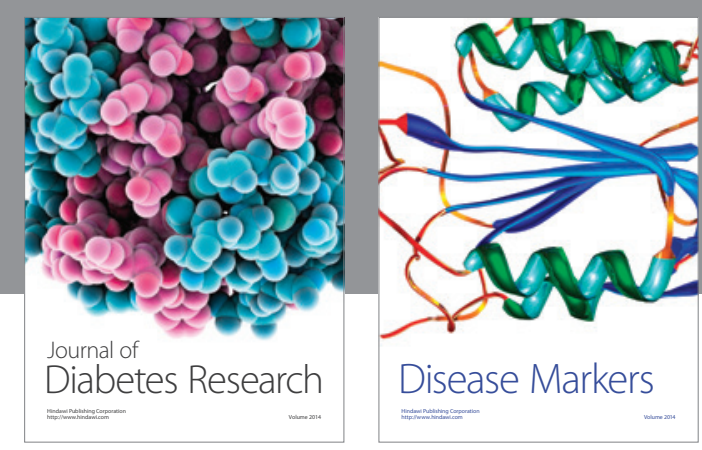

Disease Markers
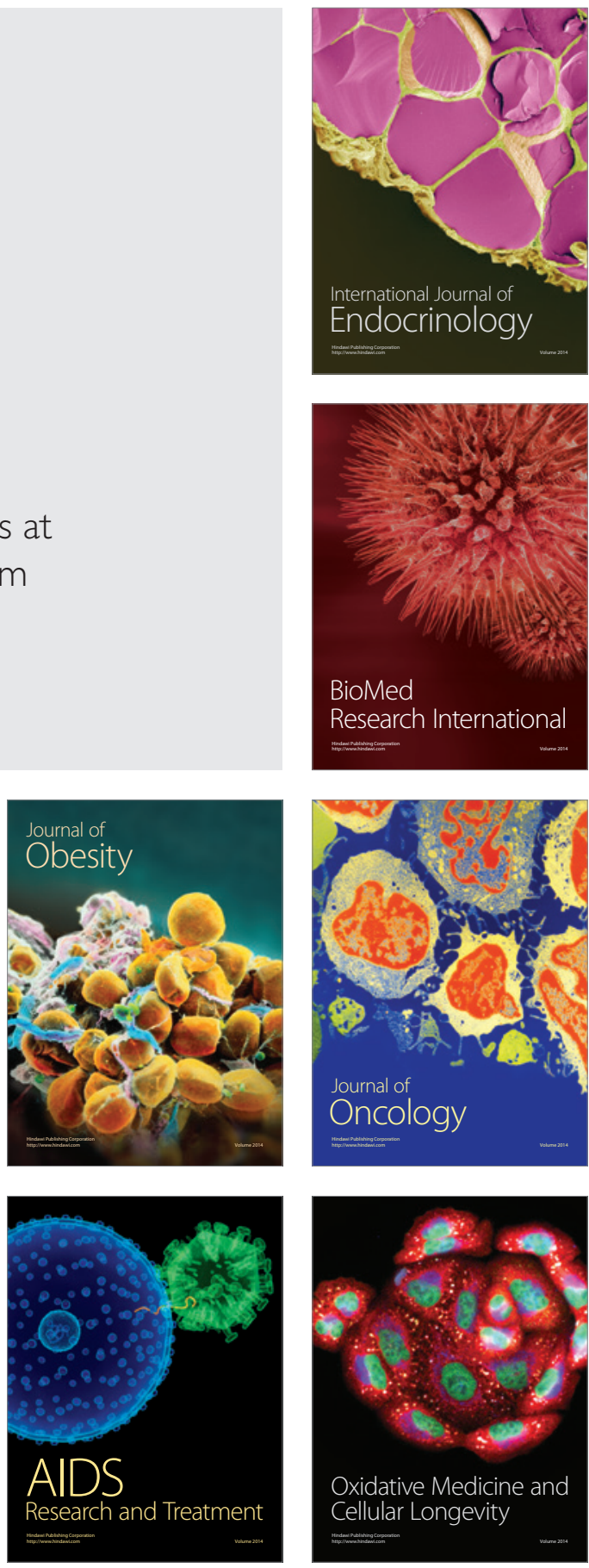